AUTORA

Maria Arminda

do Nascimento

Arruda *

arr@usp.br

${ }^{\circledR}$ Autora de contacto

* Profesora Titular de Sociología de USP y

Vice Rectora de Cultura

y Extensión de USP

\section{Sociedad y cultura modernas en Brasil. La formación de la sociologia en San Pablo}

\author{
Sociedade e cultura modernas no Brasil. A formação da sociologia em São Paulo
}

Modern society and culture in Brazil. Sociology formation in Sao Paulo

\section{RESUMEN}

La experiencia de la constitución de la sociología moderna en el Brasil fue plasmada en la intensa modernización del país, que se acentuó en el curso de la crisis de las relaciones sociales tradicionales, y más sensiblemente después de la Segunda Guerra Mundial. La sociedad brasileña seguía moviéndose en un sentido inverso al de la de la europea: mientras que en Europa se producía una pérdida de la hegemonía civilizacional, en el Brasil se daba la debacle del Estado Novo y la construcción de instituciones democráticas, acompañadas por una expansión desarrollista inédita. La USP fue producto de las nuevas concepciones que orientaban a los mentores de las instituciones culturales, quienes propugnaban la creación de organismos afines al clima imperante. En este escenario de transformaciones profundas y de apuestas modernizadoras Florestan Fernandes se destacó como personalidad singular la cual se identificó con la misión de construir las bases científicas de la sociología en el Brasil. ${ }^{1}$

\section{RESUMO}

A experiência da constituição da sociologia moderna no Brasil foi plasmada na intensa modernização do país, que se acentuou no curso da crise das relações sociais tradicionais, e mais sensivelmente depois da Segunda Guerra Mundial. A sociedade brasileira seguia movendo-se no sentido inverso ao da europeia: enquanto na Europa produzia-se uma perda da hegemonia civilizacional, no Brasil dava-se o debacle do Estado Novo e a construção de instituições democráticas, acompanhadas por uma expansão desenvolvimentista inédita. A USP foi produto das novas concepções que orientavam s mentores das instituições culturais, os quais propugnavam pela criação de organismos afins ao clima imperante. Nesse cenário de transformações profundas e de apostas modernizadoras, Florestan Fernandes destacou-se como personalidade singular que se identificou con la missão de construir as bases científicas da sociologia no Brasil.

\section{ABSTRACT}

The experience of the constitution of modern sociology in Brazil has to be with the intense modernization of the country, which worsened during the crisis of traditional social relations, and more significantly after World War II. Brazilian society was moving in an opposite direction to that of Europe: while in Europe a loss of civilizational hegemony in Brazil it produced the debacle of the Estado Novo and the building of democratic institutions. USP was a product of the new concepts that guided the mentors of cultural institutions who advocated the creation of more modern ones. In this scenario of profound transformation and modernization Florestan Fernandes stood out as an unique personality which is identified with the mission to build the scientific foundations of sociology in Brazil. 
Si fuese posible condensar en una única expresión los sentidos de los cambios vigentes en el Brasil desde 1930, tal vez pudiésemos calificarlos como inherentes a una época de tradiciones fatigadas. En todos los contextos de la vida económica, política, social y cultural hubo grandes cambios, que suscitaron otros estilos de pensar el país y dieron lugar a la aparición de una nueva generación de intelectuales, los llamados "intérpretes del Brasil" -Gilberto Freyre, Caio Prado Júnior, Sérgio Buarque de Holanda-, quienes enfrentaron, más allá de las diferencias que los caracterizan, el tema de la construcción de nuestra modernidad en los términos del lenguaje modernista ${ }^{2}$. Con ellos, el modernismo deja de ser el estilo avanzado de la literatura y de las artes y llega al ensayo; el movimiento de las vanguardias, que en su origen tuvo un fuerte acento nacional, dio condiciones propicias para la configuración de nuestras peculiaridades, y finalmente, fue posible construir una imagen del país en clave positiva. Esta imagen, que no implicaba ipso facto una perspectiva optimista sobre el futuro de la nación, se distinguía por el rechazo a las visiones basadas en la idea de la incompletitud de nuestra historia, cuyo punto de referencia eran las experiencias foráneas. El ensayismo crítico de corte modernista negó la norma culta portuguesa como forma adecuada de expresión intelectual e introdujo dicciones originales en el pasado, al mismo tiempo en que construyó retratos del Brasil que marcaron la cultura brasileña en toda su trayectoria posterior. Los ensayistas de los años treinta sentaron las bases de la reflexión moderna de las ciencias sociales brasileñas, legitimando el estilo de reflexión y de narrativa de esas disciplinas.

La experiencia de la constitución de la sociología moderna en el Brasil -si es que es posible identificarla con la formación académica de la disciplina- estaba plasmada en la intensa modernización del país, que se acentuó a partir de la década de 1930 en el curso de la crisis de las relaciones sociales tradicionales, y se acentuó sensiblemente desde los años inmediatamente posteriores al fin de la Segunda Guerra Mundial, cuando la riqueza nacional se generaba sobre todo en las actividades industriales. Ahora bien, a pesar del ritmo de los cambios, aún había en el ambiente orientaciones de tipo tradicionalista, lo que pone en evidencia la considerable mezcla de presente y pasado en el Brasil de aquellos años. La sociedad brasileña seguía moviéndose en un sentido inverso al de la de la europea: mientras que en Europa se producía una pérdida de la hegemonía civilizacional, en el Brasil se daba la debacle del Estado Novo y la construcción de instituciones democráticas, acompañadas por una expansión desarrollista inédita. En el plano cultural, la tercera década el siglo XX fue, según Antonio Candido, "un eje catalizador: un eje en torno del cual giró en cierto modo la cultura brasileña, catalizando elementos dispersos para ordenarlos en una nueva configuración. [...] En gran medida, porque generó un movimiento de unificación cultural al proyectar a escala nacional hechos que antes sólo ocurrían a escala regional” ${ }^{3}$.

Antonio Candido se refiere a lo que definió como "rutinización del modernismo", que pasó a ser el estilo dominante de expresión de las elites intelectuales y artísticas brasileñas. El ensayo sociológico de los años treinta se sitúa entre la cultura tradicional, en la medida en que representa un tipo de vida intelectual fuertemente anclado en una narrativa en la que el autor habla en nombre propio, y la vida intelectual desarrollada en marcos institucionales ${ }^{4}$. Por último, los ensayistas estaban en el origen de las ciencias sociales comprendidas en un sentido amplio y abarcador ${ }^{5}$, pues elegían como problema central de sus reflexiones los dilemas y las potencialidades del Brasil para la construcción de una sociedad moderna en tierras tropicales de colonización portuguesa. Este problema se volvió más significativo en aquellos años de franco reconocimiento del atraso de Portugal y de reordenamiento de las hegemonías mundiales.

PALABRAS CLAVE

Brasil años treinta; constitución de la sociología moderna en Brasil; USP

PALAVRAS-CHAVE Brasil nos anos trinta; constituição da sociologia moderna no Brasil;

KEYWORDS

Brazil the 30's; constitution of modern sociology in Brazil; USP 
En el seno de esas transformaciones, se creó en 1934 la Universidad de São Paulo (USP) y, con ella, la Facultad de Filosofía, Ciencias y Letras que dio cabida a la carrera de Ciencias Sociales. La USP fue producto de las nuevas concepciones que orientaban a los mentores de las instituciones culturales, quienes propugnaban la creación de organismos afines al clima imperante, aun cuando no encarnasen por completo los valores negadores de la tradición. La institución fue, por lo tanto, el fruto de la combinación de iniciativas planteadas en el plano educativo y los proyectos políticos de las elites ilustradas provenientes del pasado ${ }^{6}$. Esos aparatos institucionales modernos, que se estaban construyendo desde la tercera década, crecieron y se diversificaron en la etapa siguiente con la creación de varias fundaciones culturales $^{7}$. La Universidad posibilitó la formación sistemática de científicos dedicados a la docencia y a la investigación, además de producir una concepción diferente del conocimiento, pues construyó nuevos espacios de actuación para los practicantes de las diversas disciplinas en las nuevas carreras científicas, en especial en la Facultad de Filosofía de la USP. La introducción de procedimientos sistemáticos en la formación de profesionales resultó fundamental para la institucionalización del conocimiento característico de las ciencias sociales, el cual formaba parte de un escenario diferenciado de realización de las vocaciones científicas y compartía el clima típico de la sociabilidad académica.

En este escenario de transformaciones profundas y de apuestas modernizadoras, cuna de la sociología brasileña moderna, Florestan Fernandes (1920-1995) se destacó como la personalidad más singular entre los primeros científicos sociales egresados de la Universidad $^{8}$. Ninguno de sus contemporáneos se identificó como él con la misión de construir las bases científicas de la sociología en el Brasil; ni tampoco nadie de su generación desempeñó un papel tan prominente en el campo de la teoría, de la investigación sociológica, de la acción institucional y de la comprensión de la dimensión profesional del métier. Por esa razón, la imagen del sociólogo brasileño, hoy difundida, se inspiró en gran medida en su trayectoria personal e institucional, un estilo que se estaba desarrollando por lo menos desde mediados del siglo $X X$ como consecuencia de la fundación de la Universidad de São Paulo y del modelo de investigación introducido por la Escuela Libre de Sociología y Política de São Paulo, creada en 1933, que se combinaban con la tradición brasileña del intelectual público, especialmente notable en Río de Janeiro. El perfil del científico social se constituyó, pues, en el encuentro de esas diversas tradiciones, lo que presuponía la enseñanza sistemática de las disciplinas en moldes científicos y el compromiso con las cuestiones públicas del país. La conjunción de esos atributos incitaba a las investigaciones sistemáticas sobre los caminos del cambio que estaba en marcha, a la vez que era tributaria de las apuestas que se hacían en aquel tiempo.

En efecto, en la vivencia de los contemporáneos, al sacar a la luz la efectiva capacidad de "forjar en los trópicos ese soporte de civilización moderna", el Brasil comenzaba una época auspiciosa y llena de promesas. Se trataba, en suma, de un tiempo extremadamente dinámico, en el que la creencia en las posibilidades infinitas del desarrollo cultural era homóloga de la convicción respecto de la modernización económica, política y social de la nación, cuyo polo dinámico eran la industrialización y la urbanización aceleradas. Así, el presente aspiraba al futuro civilizado, el cual, dígase al pasar, seducía a todos los brasileños capaces de percibir las transformaciones en curso. Se produjo, en especial en São Paulo -el epicentro de las energías más vitales-, la confluencia del poder económico y político con el "mundo del espíritu". Entre dinero e intelecto se dieron ciertas analogías en el plano formal, como ha revelado Simmel, que se caracterizan por el impulso permanente de actualización.

Al lado de la objetividad impersonal que es propia a la inteligencia en razón de su contenido, se da una relación extraordinariamente estrecha que aquélla posee frente a la individualidad y frente al principio del individualismo en sí [...]. La función dual que realizan el dinero y la inteligencia resulta comprensible en la medida que se separa su contenido, el meollo de su esencia, de la aplicación que encuentra o del uso que de ella se hace ${ }^{10}$. 
En esa fase de creciente diferenciación de la cultura y de democratización del acceso a la vida cultural, combinadas con el dinamismo económico y la intensa movilidad social -esto es, con el carácter objetivo y subjetivo del dinero-, las condiciones indispensables para la igualación formal de las dos esferas estaban dadas.

A esos cambios se debe sumar el proceso de constitución de las instituciones democráticas y de creación de organismos para financiar la política desarrollista del Estado brasileño, que tuvo lugar entre 1946 y 1964. Francamente modernizadores, los gobiernos implementaban medidas de superación del atraso, lo que llevaba en consecuencia a la superación de las formas tradicionales heredadas del pasado. La sociología en el Brasil abrevó en la fuente de la modernización en marcha y eligió como problema fundamental de reflexión la formación de la sociedad moderna en el país: sus posibilidades, tensiones, impasses y dilemas en el desarrollo de las transformaciones. El tema del cambio social fue por tanto la cuestión central que ocupó a los intelectuales. Si bien el compromiso con lo moderno no era algo novedoso, pues había estado en los corazones y las mentes de los letrados brasileños al menos desde la Independencia, la novedad residía en el modo en que se pasó a reflexionar sobre el asunto: las concepciones del conocimiento científico, construidas a partir de investigaciones rigurosas, modularon el tono del debate. Aquí también el nuevo escenario brindó los fundamentos sociales del pensamiento científico, ya que el conocimiento abstracto es típico de contextos democráticos.

Lo que lleva a la abstracción y al análisis no proviene de las cosas en sí. Su origen es social: es ocasionado por el tamaño y la estructura del grupo donde el conocimiento ha de ser participado [...].

Podemos sacar la conclusión de que una sociedad democrática es más adecuada para descubrir las correlaciones abstractas entre las cosas, que una sociedad aristocrática $^{11}$
Las concepciones sociológicas de Florestan Fernandes, por un lado, muestran el peso que tuvo la sociología mannheimiana en parte esencial de sus motivaciones -como es evidente en el significado que atribuyó al papel de los intelectuales en la vida de las sociedades, tal como aparece en sus formulaciones acerca de la "civilización científica"- y, por otro lado, son también el resultado de los análisis sobre los dilemas de la modernización en el Brasil. La conciencia de que nuestra modernidad era singular no le impidió, sobre todo a lo largo de la década de 1950, admitir la posibilidad real de que se establecieran en el país los principios de una modernidad fundada en valores democráticos. En sus palabras: a pesar de que el "trasplante de la civilización occidental a una región tropical" constituyese un "proceso penoso, lleno de dificultades y de trastornos", era viable la construcción de la civilización moderna en el país, siempre que se cumpliera con ciertos requisitos tales como la expansión de la educación y la intervención racional de las ciencias sociales ${ }^{12}$. Florestan Fernandes actuó activamente en ambos campos, articulando su capacidad de acción en favor de la democratización del acceso a la enseñanza en todos los niveles y manifestando su compromiso con su propio origen popular. En efecto, él mismo había sido fruto de las mayores oportunidades en el campo educacional y de la creación de la USP, en lo que habían tenido un papel decisivo los renovadores de la educación, como lo fue Fernando de Azevedo, quien en 1944 le propuso que fuera su asistente.

Ahora bien, su apuesta por la construcción en el Brasil de los principios civilizados de la sociedad moderna mostró variaciones a lo largo de su trayectoria académica, la cual se extiende de 1945 a 1969, respectivamente las fechas de su admisión como profesor de la USP y de su alejamiento forzoso impuesto por el régimen militar instalado en 1964. Es interesante percibir el cambio que tuvo lugar a lo largo de esos años a partir de un trabajo modesto y circunscrito, en el que el sociólogo analiza la condición del marginal.

En 1945, Florestan Fernandes, sociólogo recién recibido, presenta el trabajo "Tiago 
Marques Aipobureu: Um bororo marginal" en el Seminario sobre los indios del Brasil organizado por Herbert Baudus ${ }^{13}$. El artículo se volvió a publicar por lo menos dos veces más, en 1960 y en 1975, sin modificaciones ${ }^{14}$. Si la elección del tema ya era en sí misma atractiva, más incitante aun fue el modo en que trató la biografía del indio bororo. Llaman también la atención las fechas de las publicaciones: la primera, cuando el joven científico social fue admitido en la vida universitaria; la segunda, cuando ya se había convertido en un académico de prestigio, con un reconocimiento indiscutible debido a los trabajos producidos que lo llevaron a una posición relevante; la última, cuando estaba apartado de la academia. Las tres situaciones correspondían a momentos singulares de la trayectoria de Florestan Fernandes. En los extremos coincidían fases de rupturas y de reconstitución de su vida, marcadas por la transformación del joven pobre en profesor de la Universidad de São Paulo y por la circunstancia del sociólogo reconocido que había perdido el espacio privilegiado, el lugar de excelencia en el que había depositado las apuestas profesionales y afectivas de su existencia. Este trabajo de pretensiones modestas se destaca del conjunto de sus escritos iniciales por atenerse a reflexiones sobre un caso singular ${ }^{15}$. Por otro lado, el estudio se sitúa en un punto intermedio entre los análisis sobre folklore y cultura popular y los llamados estudios etnológicos que los siguieron.

El análisis de la historia de Tiago Marques Aipobureu fue construido de modo que lo singular y lo general se esclareciesen mutuamente, relacionando abordajes micro y macrosociológicos, que llegan en el límite al registro de la psicología social. En suma, el texto se ocupaba del conflicto entre el individuo y la sociedad, de la conformación de personalidades tensionadas por situaciones que no se resolvían en el plano de las elecciones personales, de la manifestación del movimiento de negación de la herencia y de la imposibilidad de llevarlo a cabo.

Los caminos tortuosos de Tiago tenían semejanzas con el recorrido del autor, pero se distinguían en lo esencial. Situado entre dos mundos -el de las clases populares y el de la Universidad-, Florestan Fernandes, a diferencia del indio bororo, construyó una "solución activa", que le permitió romper con el extrañamiento inicial, es decir, con las dificultades naturales de una persona socialmente desarraigada para convivir en un ambiente bastante elitista como el de la Facultad de Filosofía de aquellos primeros tiempos ${ }^{16}$. Rompió con el "círculo de hierro" de su origen social a costa de mucho esfuerzo, de dedicación, trabajo y un absoluto control sobre sus actos. Hizo de la Universidad el espacio único de su autoconstrucción, y lo abrazó con la fuerza de la urgencia de alguien que no podía flaquear frente a las circunstancias adversas:

Al hablar de Florestan Fernandes, es necesario señalar que, además de la obra como sociólogo y de la acción como intelectual empeñado en los problemas de su tiempo, además de la actividad de profesor, de formador de un equipo, de creador de rumbos en la teoría y en la investigación, realizó otra obra no menos admirable: la construcción de sí mismo ${ }^{17}$.

La trayectoria de Florestan Fernandes, así como la de muchos intelectuales latinoamericanos, fue ejemplar por su modo de reproducir los caminos y los descaminos de la historia brasileña en su rumbo hacia la construcción de la moderna sociedad capitalista en el país. Como varios otros científicos sociales del continente -por ejemplo, Gino Germani en la Argentina, cuya obra encarnó "Ios dilemas y los interrogantes planteados por su época"- ${ }^{18}$, la reflexión de Florestan Fernandes -como la de todo intelectual de envergadura- se impregnó de los problemas esenciales que se fueron presentando a lo largo de su vida; tuvo además su momento privilegiado en la década de 1950, exactamente el período que dio aliento a las más diversas promesas. Fueron, en efecto, los años en que el Brasil persiguió "un ideal de modernidad caracterizado por el progreso, el autoperfeccionamiento y el perfeccionamiento ilimitado de lo social, y por la reorientación de valores, intereses, conductas e instituciones" ${ }^{\prime 19}$. Ésta fue la década de la construcción de la sociología de Florestan Fernandes y de la organización de la llamada "escuela paulista 
de sociología", que congregó a sus asistentes y cuyos trabajos afirmaron un estilo propio en las ciencias sociales en el Brasil ${ }^{20}$. Fue un período en el que una intelectualidad de nuevo estilo, especializada, elaboró ideas para la construcción de proyectos del Brasil en un intento por regenerar la nación y sacarla de un pasado al que se condenaba ${ }^{21}$. Fueron, por último, años en que se creyó en el poder de las ideas y en la fuerza de los intelectuales para producir los cambios tan esperados ${ }^{22}$; fue un tiempo de confianza en el poder transformador de las ideas y de la utilización social del conocimiento $^{23}$. En ese entonces, el ritmo de desarrollo en el Brasil superó todos los índices mundiales, lo que se combinó con una situación política de verdadera distensión y abierta a la participación y al disenso. La sociología brasileña floreció en ese suelo de promesas abiertas.

La escuela paulista de sociología, no obstante, buscó delimitar con mucha nitidez las diferencias entre la acción pública del científico social y su compromiso con el conocimiento riguroso. En esto seguía la orientación de Florestan Fernandes, que se sujetaba a la ciencia y dedicaba a ella la mayor parte de sus energías, un proyecto común a otros científicos sociales de América Latina, que tuvieron un papel central en la renovación de las disciplinas y trazaron sus rumbos futuros, como fue el caso de Gino Germani en la Argentina peronista ${ }^{24}$. Por todos los motivos mencionados, estos científicos sociales debieron configurar los nuevos papeles y modelar la nueva figura, en un espacio abierto a las estilizaciones. No es casual que Fernandes y Germani hayan sido representantes típicos de la condición de outsider: el primero por su origen social popular; el segundo por ser un inmigrante recién llegado, que "no era individualmente conocido [...] ni estaba conectado con algún movimiento intelectual visible"25. La comprensión del potencial de innovación requiere, por lo tanto, el tratamiento de las diversas disposiciones de los sujetos inmersos en el proceso, así como la manera en que adherían al nuevo estilo y se identificaban con las instituciones.
La Universidad le brindó a Florestan Fernandes oportunidades materiales y simbólicas esenciales para una persona que carecía de bienes raíces, como él mismo lo explicó en una entrevista publicada en 1975: "Nunca hubiese llegado a ser sociólogo si no hubiese sido profesor de sociología en la USP"26. Antonio Candido, compañero de ruta, se refirió del siguiente modo sobre el papel del sociólogo: "Él revolucionó la situación [...] fue él quien consolidó el espíritu y la organización científica como condición sine qua non para la calificación de un sociólogo"27. Sus preocupaciones por la afirmación de la sociología como disciplina científica requerían la definición rigurosa y clara de métodos adecuados que dieran fundamento a las investigaciones.

El sociólogo paulista percibió con claridad la magnitud de la empresa: "No debemos olvidar que estábamos en las décadas de 1940 y 1950 y que por entonces lo fundamental era construir la sociología como una ciencia empírica" ${ }^{28}$. De allí provienen la absorción de diversos aportes teórico-metodológicos y el impulso por buscar en distintas fuentes la inspiración necesaria. Florestan Fernandes no tenía preconceptos teóricos: "No debemos exorcizar ni la palabra función, ni el análisis causal que resulta de elaboraciones interpretativas estructuralfuncionalistas. Ellas son instrumentales. Lo que se debe exorcizar es una concepción naturalista de las ciencias sociales: ése es el quid de la cuestión"29. O también: "No se trataba de ver a Marx en función de los dogmatismos de una escuela política. Marx surgía directamente de sus textos y de su impacto teórico en la sociología" ${ }^{30}$. $\mathrm{O}$, en otros términos, lo fundamental era trabajar en el plano de las construcciones teóricas, distinguiendo los principios del análisis de sus desarrollos políticos. Incluso a fines de la década, cuando Florestan Fernandes paulatinamente comenzó a rever ciertas posiciones, se mostró cauteloso en cuanto a la adhesión no mediada del conocimiento a los problemas sociales:

es innegable que las influencias del medio ambiente en la formación del sociólogo brasileño son, en diversos aspectos, sumamente constructivas. En particular, 
favorecen la creación de una actitud más abierta y renovadora, ya sea respecto de las posibilidades de una síntesis teórica en la sociología, o respecto de la contribución que las ciencias sociales pueden hacer en el terreno de la aplicación. Sin embargo, ellas tienden a corromper el equilibrio que debe existir en el mundo de la ciencia entre los móviles positivos y los móviles extracientíficos de las investigaciones ${ }^{31}$.

El proyecto científico construido por Florestan Fernandes presuponía, como se ha visto, una agenda de investigación basada en concepciones rigurosas del conocimiento, cuya aplicación era intrínseca a la propia naturaleza de la ciencia. Los especialistas estarían, por tanto, en condiciones de aplicar los resultados de las investigaciones para modificar sistemas de relaciones por medio de nuevos descubrimientos forjados en el enfrentamiento con las cuestiones sociales. En el campo de la sociología, el especialista representaría la figura del profesional de la corporación científica, un observador de los fenómenos sociales capaz de formular reglas explicativas y de proponer medidas correctivas. El problema fundamental de la sociología en el Brasil residía, de acuerdo con sus concepciones, en la necesidad de refinar los métodos de la ciencia aplicada de manera de readaptarlos para el análisis de sociedades más heterogéneas y menos orgánicas, como la brasileña. Su rechazo de las formas de conocimiento sujetas al movimiento social dominante no significaba, pues, la desaprobación de las iniciativas de intervención. Por el contrario, sentía gran aprecio por las contribuciones de la Escuela Sociológica de Chicago: "Debido a las analogías entre Chicago y São Paulo y a nuestros propósitos de expandir aquí la investigación sociológica, el intento de hacer de São Paulo un laboratorio (o un campo especial de trabajo concentrado de los sociólogos) atraía lo mejor de mi imaginación"32. La institución universitaria moderna sería el locus de legitimación para el desarrollo de propuestas de intervención social, el foro privilegiado de los patrones de trabajo necesarios para la construcción de la sociología científica en el país. Esta comprensión de la sociología orientó los objetivos de investigación de Florestan Fernandes, que combinó trabajos eminentemente teóricos y metodológicos incluso sus tesis en el terreno de la etnología fueron sustancialmente vigorosos ejercicios teóricos ${ }^{33}$ con otros dedicados al estudio de la civilización industrial y de la formación de la sociedad de clases, es decir, de la moderna sociedad burguesa en un contexto atravesado por orientaciones valorativas derivadas del pasado esclavista.

A integração do negro na sociedade de classes, tesis presentada para el concurso de una cátedra en Sociología en marzo de 1964 -cargo que ocupaba de hecho desde 1954 como profesor interino de Sociología I, debido al regreso de Roger Bastide a Francia-, representó un cambio de inclinación en la perspectiva analítica de Florestan Fernandes. La tesis -una monografía ejemplar- retomaba su interés por el tema de las relaciones raciales y del prejuicio racial, que ya había tratado con la investigación promovida por la UNESCO en diferentes regiones del Brasil, entre 1949 y 1951, y realizada en colaboración con Roger Bastide. La obra reveló la madurez de la reflexión del sociólogo acerca del proceso de constitución del Brasil moderno, lo que se pone en evidencia en la franca marcha atrás con respecto a su apuesta sobre las posibilidades efectivas de construir en el Brasil los principios civilizadores modernos. Al situar la problemática del negro en el pasaje de la sociedad esclavista a la sociedad de clases, el sociólogo analizó las relaciones raciales bajo el prisma de la dinámica global de la modernización brasileña, que se había desarrollado con mayor fuerza en la ciudad de São Paulo. La rápida transformación urbana que tuvo lugar entre fines del siglo XIX y comienzos del $X X$ imposibilitó la inserción del negro y del mulato en el estilo de vida urbano, ya que no contaban con recursos para enfrentar la competencia de los inmigrantes. $\mathrm{O}$, para usar sus categorías, la heteronomía existente en la "situación de castas" impidió que los negros asimilaran las potencialidades que ofrecía la "situación de clases". De ese proceso resultan el "desajuste estructural" y la "desorganización social", que caracterizan la situación de los descendientes de los africanos, relegados así a vivir en un estado de marginalidad social como verdaderos proscritos de las conquistas 
civilizadas. El prejuicio y otras manifestaciones de discriminación ejercieron la función "de mantener la distancia social" y de reproducir el "aislamiento sociocultural", cuyo propósito no era otro que la preservación de las "estructuras sociales arcaicas". En São Paulo, el ritmo intenso de la historia produjo un fuerte desfase entre el orden social (más sincronizado con las transformaciones de la estructura económica) y el orden racial (más lento en su adaptación a los cambios), que se mantuvo como una especie de "residuo del antiguo régimen", cuya eliminación futura resultaría de los "efectos indirectos de la normalización progresiva del estilo democrático de vida y del orden social correspondiente".

En esos pasajes se explicita la comprensión de la particular realización de la sociedad moderna en el Brasil: un proceso complejo y de resultados híbridos, ya que, a pesar del ritmo de las transformaciones, existe una especie de debilidad congénita que compromete a todo el desarrollo posterior. Los análisis sobre el legado de la esclavitud formaban parte, así, del intento por comprender el modo en que los fundamentos de la sociedad brasileña bloqueaban y obstaculizaban la plena consecución de principios civilizados y de una modernidad capitalista pura. El proyecto de investigar el papel de las relaciones esclavistas en la constitución de la sociedad nacional se extendió con los trabajos escritos por sus asistentes, como Fernando Henrique Cardoso, Octávio lanni, Maria Sylvia de Carvalho Franco, entre otros colaboradores. La articulación de los temas de investigación dio sus frutos y produjo afinidades intelectuales en el grupo reunido por Fernandes, lo que justifica la identificación construida más tarde y sintetizada en la expresión "escuela paulista de sociología", aun cuando la convivencia no hubiese sido siempre pacífica y hubiera diferencias internas entre los participantes.

El sentimiento de evidente escepticismo que recorre las páginas de $A$ integração do negro na sociedade de classes señalaba el fin de las reflexiones sistemáticas del sociólogo sobre el tema, quien emprendió entonces un nuevo proyecto: Economia e sociedade no Brasil: análise sociológica do subdesenvolvimento, seguido del plan de estudio $A$ empresa industrial em São Paulo. Concebidos junto con Fernando Henrique Cardoso, los proyectos tenían la finalidad de orientar las investigaciones del Centro de Sociología Industrial y del Trabajo (CESIT), creado en 1962 con financiamiento público y privado. Durante los nueve años de existencia del CESIT, se llevaron a cabo importantes trabajos, basados en las investigaciones implementadas y en amplios sondeos, que procuraban conocer de modo sistemático y riguroso los rumbos de la modernización brasileña y las particularidades de la "civilización industrial en el Brasil". La creación del CESIT representó el ingreso definitivo de los sociólogos paulistas en el debate sobre el desarrollo del país, que se incorporaron así al coro de los científicos sociales que formulaban proyectos referidos al desarrollo nacional, como era el caso de los científicos sociales del Instituto Superior de Estudios Brasileños (ISEB), con sede en Río de Janeiro y patrocinado por el Estado. La creación del centro paulista, radicado en la USP, sumada a la proverbial vitalidad del ISEB y a la experiencia innovadora de la carrera de Sociología y Política, de la Facultad de Ciencias Económicas de la Universidad de Minas Gerais, era muestra del vigor y de la relevancia que habían adquirido las ciencias sociales en el Brasil a lo largo de los años posteriores a los traumáticos acontecimientos de la posguerra. Había un clima de franca apuesta en el desarrollo de los países latinoamericanos, de lo cual la Comisión Económica para América Latina (CEPAL) era un ejemplo contundente. Con $A$ integração do negro na sociedade de classes, el sociólogo destacaba la presencia de impasses inherentes a un proceso de modernización sin vigor para superar el legado del pasado; la debilidad de lo moderno terminó dando aliento a la tradición, cuando se combinó con ésta. Con el libro A revolução burguesa no Brasil. Ensaio de interpretação sociológica, esas concepciones dieron urdimbre a la obra, lo que llevó al sociólogo a desarrollar categorías adecuadas para el tratamiento de los problemas y los obstáculos típicos de sociedades que no realizan las formas avanzadas de la civilidad moderna. 
A revolução burguesa no Brasil es fundamental para explicitar la trayectoria del sociólogo ${ }^{34}$. Se trata de una obra importante, cuyo objeto es el análisis del proceso histórico de la formación de la sociedad burguesa en el Brasil, desde la Independencia hasta las transformaciones producidas por el golpe militar de 1964. Este texto, lleno de matices, expone un nítido clivaje en el pensamiento del autor, lo que se manifiesta en el propio cuerpo del análisis. Escrito entre 1966 y 1974, tuvo una interrupción en su proceso de elaboración de casi tres años, período en el que Florestan Fernandes dictó clases en la Universidad de Toronto. El autor explicó de entrada el modo en que percibía su proyecto:

Es necesario que el lector entienda que no proyectaba hacer una obra de "sociología académica". Por el contrario, pretendía resumir, en el lenguaje más simple posible, las principales líneas de la evolución del capitalismo y de la sociedad de clases en el Brasil. Se trata de un ensayo libre, que no podría haber escrito si no fuera sociólogo; pero que pone en primer plano las frustraciones y las esperanzas de un socialista militante ${ }^{35}$.

Ahora bien, más allá de las intenciones declaradas del autor, el libro es un ejercicio académico de interpretación, en el que las peculiaridades de ese estilo se encuentran en abundancia. A partir de una indagación sobre el significado para la realidad brasileña de las nociones de "burgués", "burguesía" y "revolución burguesa", procura "establecer de manera preliminar ciertas cuestiones de alcance heurístico"36. El problema decisivo de la obra se plantea en la discusión acerca de la especificidad de la construcción de la sociedad de clases y de la revolución burguesa en el Brasil, vistas desde la perspectiva de la constitución de la racionalidad burguesa, de la mentalidad burguesa, esto es, de una ética de la "ganancia", del "lucro" y del "riesgo calculado" 37 . Se trata, por lo tanto, de la génesis de la sociedad moderna en el Brasil y del desarrollo de la sociedad de clases, cuestiones que recorren la primera parte dedicada al estudio del proceso de la Independencia y del desencadenamiento de la revolución burguesa. Para el análisis de ese período de formación, el autor examinó el universo valorativo que orientaba las acciones de los agentes implicados, apuntando hacia el hecho de que la mentalidad económica de la colonia "estaba sujeta a una distorsión inevitable"38. Naturalmente, el análisis pone en juego dimensiones psicosociales para la caracterización del "espíritu burgués".

La construcción de la sociedad nacional a partir de la Independencia y del liberalismo, como doctrina de acción de las "elites nativas", es crucial, pues a partir de ello es posible vislumbrar la emergencia de nuevos valores que orientan la acción. En otros términos, el liberalismo produce "formas de poder específicamente políticas y organizadas lucrativamente" $y$, para una parte de la sociedad, exige la "libre competencia" 39 . Surgía, entonces, "un área en la que el 'sistema competitivo' puede coexistir y chocar con el 'sistema estamental'"'40. El liberalismo estaba en la base del surgimiento y de la estructuración de la sociedad nacional, pero al mezclarse con elementos de la historia pasada no siempre logró superarlos ${ }^{41}$. Con ello se pone de relieve la especificidad de la formación histórica brasileña, lo que le permitió discutir la problemática de nuestra revolución burguesa. En sus palabras,

se trata de [...] determinar cómo se procesó la absorción de un patrón estructural y dinámico de organización de la economía, de la sociedad y de la cultura. Sin la universalización del trabajo asalariado y la expansión del orden social competitivo, ¿cómohabríamosdeorganizarunaeconomía de mercado sobre bases monetarias y capitalistas? Es desde esa perspectiva que el "burgués" y la "revolución" aparecen en el horizonte del análisis sociológico. No tuvimos todo el pasado de Europa, pero reprodujimos de forma peculiar su pasado reciente, pues éste era parte del propio proceso de implantación y de desarrollo de la civilización occidental moderna en el Brasil. Hablar de revolución burguesa, en ese sentido, consiste en buscar los agentes humanos de las grandes transformaciones histórico-sociales que están por detrás de 
la desagregación del régimen esclavistaseñorial y de la formación de una sociedad de clases en el Brasil ${ }^{42}$.

Centrada en la dinámica social de los agentes, la reflexión pretende comprender "la formación del llamado 'Brasil moderno', florecimiento cultural de la silenciosa revolución socioeconómica en la que aquella revolución política habría de desarrollarse, lentamente, a lo largo del tiempo" ${ }^{43}$. En suma, el análisis busca recuperar la génesis de esa identidad problemática, que está en el corazón de la historia brasileña y a cuya combinación de elementos dispares puede atribuirse nuestra particularidad.

La segunda parte del libro -"A formação da ordem social competitiva"- es un fragmento. Como alude el propio título, el autor se dedica a entender la formación del orden social competitivo en países de origen colonial, como el Brasil.

En las "sociedades nacionales"
dependientes, de origen colonial, el
capitalismo es introducido antes de la
constitución del orden social competitivo.
Él se enfrenta con estructuras económicas,
sociales y políticas construidas bajo
el régimen colonial, sólo parcial y
superficialmente ajustadas a los patrones
capitalistas de vida económica ${ }^{44}$.

Una vez más, Florestan Fernandes localiza el problema de nuestra historia en la incapacidad o la imposibilidad de superar los principios inherentes al orden social anterior. Las nociones de capitalismo dependiente y de orden social competitivo estructuran el análisis, lo que permite comprender los límites del "estilo competitivo de vida social" y de la "mentalidad económica racional". El problema que se plantea es detectar al agente social que mejor encarne la condición burguesa de vida. Una burguesía mercantil urbana, denominada "estamento social intermediario" 45 , expresaba los nuevos valores sociales, pero a pesar de ello no pudo, o no fue capaz de romper con el círculo poderoso que venía del pasado.

Aquí cabe destacar, en especial, la estrecha vinculación que se estableció, genéticamente, entre intereses y valores sociales sustancialmente conservadores (o, en otras terminologías: particularistas y elitistas) y la constitución del orden social competitivo. Por sus raíces históricas, económicas y políticas, ella ató el presente al pasado como si fuese una cadena de hierro. Si la competencia contribuyó, en un momento histórico, a acelerar la decadencia y el colapso de la sociedad de castas y estamentos, en otro momento, ella encadenó la expansión del capitalismo a un privatismo tosco, rígidamente particularista y fundamentalmente autocrático, como si el "burgués moderno" renaciese de las cenizas del "señor antiguo"46.

Dado que las actividades comerciales, dirigidas al mercado interno y de cuño capitalista, no fueron capaces de desconectarse de la lógica que presidía el movimiento del pasado, sus agentes afirmaron los mismos criterios estamentales del orden esclavista y diseñaron un estilo de vida semejante al de la aristocracia agraria ${ }^{47}$. El producto final refleja una sociedad cuyos bloqueos impidieron el surgimiento pleno del orden social competitivo y de los criterios inherentes a una estructura de clases, lo que tuvo visibles y dañinas consecuencias para la construcción de "relaciones sociales superiores" ${ }^{48}$.

En la tercera parte -"Revolução burguesa e capitalismo dependente"- se analiza la génesis de la forma de acumulación capitalista dependiente así como la especificidad de su realización. Florestan Fernandes se refiere otra vez a la particularidad de la estructura de clases, del mundo burgués y de la burguesía en el Brasil. Incapaz de independizarse de la oligarquía y de realizar las tareas típicas de su congénere europea -como la creación de la nación-, así como de convertirse en el agente fundamental de las transformaciones, la burguesía brasileña experimentó el dilema histórico de su situación de clase. Se amalgamó a fuerzas sociales retrógradas y no implementó la democracia liberal; el Estado fue la columna vertebral de los cambios, pues la clase burguesa no llevó adelante el proceso de industrialización. Por todo ello, 
el capitalismo dependiente es, por su propia naturaleza y en general, un capitalismo difícil, lo que deja sólo unas pocas alternativas efectivas a las burguesías que le sirven, a un mismo tiempo, de parteras y de viejas nodrizas. Desde esa perspectiva, la reducción del campo de acción histórica de la burguesía expresa una realidad específica, a partir de la cual la dominación burguesa aparece como conexión histórica no de la "revolución nacional y democrática", sino del capitalismo dependiente y del tipo de transformación capitalista que él supone ${ }^{49}$.

Los impasses de la burguesía son las encrucijadas de una historia dependiente de los centros hegemónicos, cuyas fuerzas internas no son capaces de romper las ataduras externas. El orden capitalista tropieza con la ingerencia externa, debido a sus diferentes patrones de desarrollo, los cuales a su vez producen una solidaridad entre contrarios. Es por ese motivo que el análisis de la "revolución burguesa en el Brasil consiste en la crisis del poder burgués, que se localiza en la época actual y surge como consecuencia de la transición del capitalismo competitivo al capitalismo monopólico"50. Y a partir de ese momento, los clivajes se manifiestan con toda contundencia. Se trata de rupturas que atañen al sentido del análisis y de las categorías que lo informan. Los dos últimos capítulos -"Natureza e etapas do desenvolvimento capitalista" y "O modelo autocrático-burguês de transformação capitalista"- son esclarecedores respecto de esos cambios.

La envergadura de la reflexión desarrollada, la amplitud del período tratado, el estilo ensayístico y sobre todo la consideración del problema de la formación histórica de la sociedad brasileña permiten inscribir la obra dentro de la tradición de los textos fundamentales de interpretación del Brasil, que paradójicamente fue concluida en el momento en que las opciones de Florestan Fernandes se alejaban de la universidad. Es aun más significativo poner de relieve el giro que realizó en relación con sus concepciones acerca del ensayo dedicado a tratar la formación histórica de la nación brasileña, al que no consideraba una expresión legítima de la sociología científica e identificaba con la forma estamental de la vida intelectual; más aun, en ese sentido, también había afirmado la incompatibilidad entre la sociología científica y los procedimientos de la reconstrucción histórica típica de los ensayos ${ }^{51}$. El autor no sostuvo el mismo carácter sistemático de organización de las ideas ni la misma creencia en la inadecuación de la forma ensayística para el discurso científico52. "Noción a un mismo tiempo descriptiva y normativa" 53 , el principio de la "formación" y su recurrencia en el pensamiento brasileño revelan cuestiones decisivas de orden intelectual ${ }^{54}$. Un tipo de avatar del intelectual en la periferia del mundo, la primacía del ideal de la "formación" permite que se contornee el sentimiento de la artificialidad de nuestra cultura, de la ausencia de línea evolutiva, de la inexistencia de "seriación" en las ideas, de la persistencia de nuestra "indiferencia", según Sílvio Romero, como resultado del constante dominio de la importación intelectual externa sobre la tradición local ${ }^{55}$.

Con la aceptación de la forma ensayística, Florestan Fernandes se desviaba del patrón discursivo que antes había afirmado, sin por ello apartarse de los análisis rigurosos y fundamentados sociológicamente. Desde su apuesta por la constitución de la sociedad moderna en los trópicos, pasando por la constatación de la fragilidad de la aclimatación de esos valores en el Brasil, hasta la confirmación de la imposibilidad de que el país alcance el estadio de una real civilización, el sociólogo recorrió un trayecto en el que los rumbos de la historia brasileña se mezclaron con su biografía y con su sociología. Las ediciones de "Tiago Marques Aipobureu: Um bororo marginal" son reveladoras de su obra y de su trayectoria, pues simbolizan la profunda imbricación entre su historia de vida y la historia brasileña y exponen, de manera penetrante, el modo en que sus circunstancias personales se confundieron con los problemas del Brasil. En ese contexto, es posible entender las diferentes maneras en que fue reflexionando sobre la experiencia del país en el transcurso de la modernización. Florestan Fernandes reorientó sus apuestas, adhiriendo a la política partidaria, intentando contornear uno de los pilares de sus análisis sociológicos que 
revelaban los efectos imprevistos e inusitados de la acción humana en el mundo, defasaje que, de acuerdo con su obra, se profundizaba en sociedades como la brasileña. Es posible que allí resida, exactamente, su principal aporte para una nueva concepción sobre la formación de la sociedad moderna en el Brasil.

\section{NOTAS}

${ }^{1}$ Resumen y palavras clave elaborados por el Consejo de Dirección de REB.

${ }^{2}$ Investigué en otro texto la relación entre los ensayos de 1930 y el modernismo: M. A. do N. Arruda, "Pensamento brasileiro e sociologia da cultura: Questões de interpretação", Clio, Revista do Centro de História da Universidade de Lisboa, vol. 14, pp. 131-141, 2006. Para un análisis diferenciado sobre las relaciones entre la obra de Gilberto Freyre y el modernismo, véase R. B. de ARAÚJO. Guerra e paz. Casa- grande \& senzala e a obra de Gilberto Freyre nos anos 30. $2^{a}$ ed. São Paulo, 34, 2005

${ }^{3}$ Antonio CANDIDO. A educação pela noite e outros ensaios. São Paulo: Ática, 2000, pp. 181-182.

4 "El nombre propio de quien firma el ensayo es uno de los elementos clave del género: al asumir la primera persona, el ensayista asume también un compromiso explícito con el lector, al que se propone un pacto de lectura que, con su nombre propio, asume la responsabilidad de los enunciados" (S. SAÍTTA, "Modos de pensar lo social. Ensayo y sociedad en la Argentina (1930-1965)", en F. Neiburg y M. Plotkin (comps.), Intelectuales y expertos. La constitución del conocimiento social en la Argentina, Buenos Aires, Paidós, 2004, p. 108. R. B. de ARAúJO analiza en qué medida Gilberto Freyre es el personaje de su propio libro, al presentarse "tanto como su creador cuanto como su criatura", op. cit., p. 199.

${ }^{5}$ Cf. R. B. de Araújo, op. cit., p. 17.

${ }^{6}$ Cf. I. CARDOSO. A universidade da comunhão paulista, São Paulo, Cortez, 1982.
${ }^{7}$ Cf. M. A. do N. ARRUDA. Metrópole e cultura: São Paulo no meio século XX, Bauru, EDUSC, 2001.

8 Para un análisis diferenciado de la biografía y la formación intelectual de Florestan Fernandes, véase S. G. GARCIA. Destino ímpar. Sobre a formação de Florestan Fernandes. São Paulo: 34, 2002. Para el tratamiento del carácter moderno y pionero de la sociología de Florestan Fernandes, véase $\mathrm{M}$. A. do N. ARRUDA; G. GARCIA. Florestan Fernandes. Mestre da sociologia moderna. Brasilia: Paralelo 15, 2003.

${ }^{9}$ Frase acuñada por Florestan FERNANDES. A integração do negro na sociedade de classes. No limiar de uma nova era. São Paulo: Dominus/Edusp, 1965, v. II, p. 394.

${ }^{10}$ SIMMEL, G. The philosophy of money. Londres: Routledge, 1997, p. 437 [la cita corresponde a la edición en español: Filosofía del dinero, trad. de Ramón García Cotarelo, Madrid, Instituto de Estudios Políticos, 1977, p. 548].

${ }^{11}$ MANNHEIM, K. Ensayos de sociología de la cultura. Hacia una sociología del espíritu, el problema de la "inteligenstia", la democratización en la cultura. Madrid: Aguilar, 1957, p. 265.

12 FERNANDES, Florestan. Mudanças sociais no Brasil, $2^{a}$ ed. São Paulo: Difel, 1974, p. 311. Las referencias siguientes a esta obra pertenecen a la segunda edición.

${ }^{13}$ FERNANDES, Florestan. Tiago Marques Aipobureu: Um bororo marginal. En A investigação etnológica no Brasil e outros ensaios. Petrópolis: Vozes, 1975. Florestan Fernandes se vale del material recogido por Herbert Baldus, Antônio Colbacchini y César Albisetti. Cf. p. 85.

${ }^{14}$ La primera edición del trabajo apareció en la Revista do Arquivo Municipal, São Paulo, vol. LVII, 1946; la segunda, en Mudanças sociais no Brasil, São Paulo, Difusão Européia do Livro, 1960; la tercera fue la edición utilizada.

${ }^{15}$ José de Souza Martins analiza los estudios biográficos de Florestan Fernandes. Cf. J. de S. MARTINS, "Vida e história na sociologia de Florestan Fernandes. Reflexões sobre o método da história de vida", en Florestan. Sociologia e consciência social no Brasil, São Paulo, Edusp, 1998. También fue publicado en la Revista USP, vol. 29, pp. 14-19, marzo-mayo de 1996. Además de referirse al texto sobre Tiago Marques, Martins se ocupa de la investigación que Florestan Fernandes realizó en Sorocaba sobre el líder carismático João de Camargo y del conjunto de textos reunidos en A contestação necessária (Retratos intelectuais de inconformistas e revolucionários), São Paulo, Ática, 1995. Este último libro reúne escritos que trazan perfiles de amigos, de compañeros de partido o de intelectuales brasileños y latinoamericanos que sostuvieron posiciones radicales. Es una obra que pertenece al campo de la historia intelectual. 
16 "Como figura humana, yo sería aquello que los historiadores, los antropólogos y los sociólogos definen como una personalidad desarraigada. Soy un desarraigado" (FERNANDES, Florestan. A condição de sociólogo, São Paulo, Hucitec, 1978, p. 30).

${ }^{17}$ CANDIDO, Antonio. Nota final. En Lembrando Florestan Fernandes. São Paulo: Edição Particular, 1996, p. 63.

18 BLANCO, A. Razón y modernidad. Gino Germani y la sociología en la Argentina. Buenos Aires: Siglo XXI, 2006, p. 19.

${ }^{19}$ BOTELHO, A. Uma sociedade em movimento e sua intelligentsia: apresentação. En A. BOTELHO, E. R. BASTOS; G. VILLAS BOAS (comps.). O moderno em questão. A década de 1950 no Brasil. Rio de Janeiro: Topbooks, 2008, p. 15

${ }^{20}$ Cf. M. A. do N. Arruda, Metrópole e cultura, op. cit.

${ }^{21}$ Cf. E. R. BASTOS. O outro Brasil de Luís Amaral. En A. BOTELHO; E. R. BASTOS; G. VILLAS BOAS (comps.). O moderno em questão, op. cit., pp. 27-64.

${ }^{22}$ Cf. G. Villas Boas, Mudança provocada. Passado e futuro no pensamento sociológico brasileiro, Río de Janeiro, FGV, 2006.

${ }^{23}$ Sobre el proyecto de intervención de la sociología de Florestan Fernandes, véase M. A. do N. ARRUDA y G. GARCIA. Florestan Fernandes. Mestre da sociologia moderna, op. cit., en especial la segunda parte.

${ }^{24}$ Cf. F. NEIBURG. Os intelectuais e a invenção do peronismo. São Paulo: Edusp, 1997, pp. 157-184.

${ }^{25}$ A. Blanco, Razón y modernidad, op. cit., p. 244.

${ }^{26}$ Entrevista a Florestan Fernandes, en Transformação, Facultad de Filosofía, Ciencias y Letras de Assis, 1975, p. 39.

27 "Prefácio", en A condição de sociólogo, op. cit.

${ }^{28}$ Entrevista a Florestan Fernandes, en Transformação, art. cit., p. 12

${ }^{29}$ Ibid., p. 56.

${ }^{30}$ Ibid., p. 14.

${ }^{31}$ FERNANDES, Florestan. A etnologia e a sociologia no Brasil. São Paulo: Anhembi, 1958, p. 213.

32 FERNANDES, Florestan. A sociologia no Brasil. $2^{a}$ ed. Petrópolis: Vozes, 1980, p. 170. "Son varias las resonancias de la Escuela de Chicago en el Departamento de Ciencias Sociales de la USP en cuanto a la agenda reformadora y al deseo de que su investigador se sumerja en la vida local" (L. W. Vianna, A revolução passiva. Iberismo e americanismo no Brasil, Río de Janeiro, Revan, 1997, p. 190).
${ }^{33}$ Me refiero a su maestría -Organização social dos tupinambá, São Paulo, Progresso, s/f-y al doctorado -A função social da guerra na sociedade tupinambá, $2^{a}$ ed., São Paulo, Pioneira, 1970-. Este libro es considerado una obra capital de la antropología social.

${ }^{34}$ FERNANDES, Florestan. A revolução burguesa no Brasil. Ensaio de interpretação sociológica. Rio de Janeiro: Zahar, 1975.

${ }^{35}$ lbid., pp. 9-10

${ }^{36}$ Ibid., p. 15.

${ }^{37}$ El autor se vale de las categorías de Sombart; cf. p. 16.

38 lbid., p. 25.

${ }^{39}$ Ibid., p. 48.

40 Ibid.

${ }^{41}$ Cf. ibid., p. 39. Para su análisis de las dimensiones ideológicas y utópicas del liberalismo, Florestan Fernandes se basa en Karl Mannheim.

${ }^{42}$ Ibid., p. 20.

${ }^{43}$ Ibid., p. 71.

44 Ibid., p. 149

${ }^{45}$ Cf. Ibid., p. 160

${ }^{46}$ Ibid., pp. 167-168.

${ }^{47}$ Cf. Ibid., p. 183

${ }^{48}$ Cf. Ibid., pp. 196-197.

49 Ibid., p. 214

50 Ibid., p. 215

${ }^{51}$ Cf. F. Fernandes, A sociologia numa era de revolução social, São Paulo, Nacional, 1963, p. 230. Véase también F. Fernandes, O padrão do trabalho científico dos sociólogos brasileiros, Río de Janeiro, Edição da Revista Brasileira de Estudos Políticos, 1958, pp. 45-46.

${ }^{52}$ Cf. M. A. do N. Arruda, Metrópole e cultura, op. cit., p. 315 .

${ }^{53}$ P. E. Arantes, "Providências de um crítico literário na periferia do capitalismo", en O. B. F. Arantes y P. E. Arantes, Sentido da formação: três estudos sobre Antônio Candido, Gilda de Melo e Souza e Lúcio Costa, São Paulo, Paz e Terra, 1997, p. 12.

${ }^{54}$ Cf. Ibid.

55 lbid. 


\section{BIBLIOGRAFÍA}

ARANTES, P. E. Providências de um crítico literário na periferia do capitalismo. En O. B. F. ARANTES; P. E.

ARANTES. Sentido da formação: três estudos sobre Antônio Candido, Gilda de Melo e Souza e Lúcio Costa. São Paulo: Paz e Terra, 1997.

ARAÚJO, R. B. de. Guerra e paz. Casa- grande \& senzala e a obra de Gilberto Freyre nos anos 30. $2^{\mathrm{a}}$ ed. São Paulo, 34, 2005.

ARRUDA, Maria Arminda do Nascimento. Metrópole e cultura: São Paulo no meio século XX, Bauru, EDUSC, 2001

G. GARCIA. Florestan Fernandes. Mestre da sociologia moderna. Brasilia: Paralelo 15, 2003.

BLANCO, A. Razón y modernidad. Gino Germani y la sociología en la Argentina. Buenos Aires: Siglo XXI, 2006

BOTELHO, A. Uma sociedade em movimento e sua intelligentsia: apresentação. En A. BOTELHO, E. R. BASTOS; G. VILLAS BOAS (comps.). O moderno em questão. A década de 1950 no Brasil. Rio de Janeiro: Topbooks, 2008.

CANDIDO, Antonio. A educação pela noite e outros ensaios. São Paulo: Ática, 2000.

Nota final. En Lembrando Florestan Fernandes. São Paulo: Edição Particular, 1996.

CARDOSO, I. A universidade da comunhão paulista, São Paulo, Cortez, 1982.

GARCIA, S. G. Destino ímpar. Sobre a formação de Florestan Fernandes. São Paulo: 34, 2002.

FERNANDES, Florestan. A condição de sociólogo, São Paulo, Hucitec, 1978

A etnologia e a sociologia no

Brasil. São Paulo: Anhembi, 1958.

A integração do negro na

sociedade de classes. No limiar de uma nova era. São Paulo: Dominus/Edusp, 1965, v. II

- A revolução burguesa no Brasil. Ensaio de interpretação sociológica. Rio de Janeiro: Zahar, 1975

Petrópolis: Vozes, 1980.

A sociologia no Brasil. $2^{\mathrm{a}}$ ed

A sociologia numa era de revolução social. São Paulo: Nacional, 1963.

Mudanças sociais no Brasil, $2^{\mathrm{a}}$

ed. São Paulo: Difel, 1974
Tiago Marques Aipobureu: Um bororo marginal. En A investigação etnológica no Brasil e outros ensaios. Petrópolis: Vozes, 1975

MANNHEIM, K. Ensayos de sociología de la cultura. Hacia una sociología del espíritu, el problema de la "inteligenstia", la democratización en la cultura. Madrid: Aguilar, 1957.

MARTINS, José de Souza. Vida e história na sociologia de Florestan Fernandes. Reflexões sobre o método da história de vida. En Florestan. Sociologia e consciência social no Brasil. São Paulo: Edusp, 1998.

NEIBURG, F. Os intelectuais e a invenção do peronismo. São Paulo: Edusp, 1997.

SAITTA, S. Modos de pensar lo social. Ensayo y sociedad en la Argentina (1930-1965). En F. Neiburg y M. Plotkin (comps.), Intelectuales y expertos. La constitución del conocimiento social en la Argentina, Buenos Aires, Paidós, 2004.

SIMMEL, G. Filosofía del dinero, trad. de Ramón García Cotarelo. Madrid: Instituto de Estudios Políticos, 1977.

VIANNA, L. W. A revolução passiva. Iberismo e americanismo no Brasil. Rio de Janeiro: Revan, 1997.

VILLAS BOAS, G. Mudança provocada. Passado e futuro no pensamento sociológico brasileiro. Rio de Janeiro: FGV, 2006 